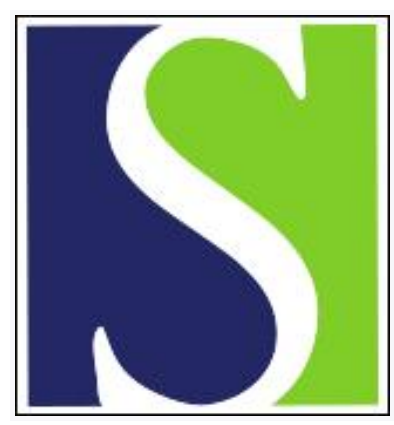

Scand J Work Environ Health 2014;40(1):101-102

https://doi.org/10.5271/sjweh.3404

Published online: 19 Nov 2013, Issue date: 01 Jan 2014

The prevalence and incidence of carpal tunnel syndrome in US working populations

by Shiri R

Affiliation: Centre of Expertise for Health and Work Ability, Finnish Institute of Occupational Health, Topeliuksenkatu 41 a A FIN-00250 Helsinki. Email: rahman.shiri@ttl.fi

Refers to the following text of the Journal: 2013;39(5):495-505

Key terms: carpal tunnel syndrome; CTS; epidemiology; incidence; letter to the editor; letter to the editor; musculoskeletal disorder; prevalence; USA

This article in PubMed: www.ncbi.nlm.nih.gov/pubmed/24252999

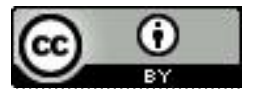




\section{The prevalence and incidence of carpal tunnel syndrome in US working populations}

In the September issue of the Scandinavian Journal of Work, Environment and Health, Dale et al (1) estimated the prevalence and incidence of carpal tunnel syndrome (CTS) by pooling the raw individual-level data of six diverse prospective studies in US working populations. Simply adding up the numbers of participants and events (CTS) from different studies is an inappropriate method to analyze individual participant data as it treats the data as if they were from one large study (2). The analysis should calculate a weighted average for each study and account for the clustering of participants within different studies $(2,3)$.

There was significant between-study heterogeneity. $\mathrm{I}^{2}$ statistic (4) was 93\% [95\% confidence interval (95\% CI) 88-96\%] for both prevalence and incidence. The six studies differed in regard to sample size, age, sex, education, occupation, race, ethnicity, employment duration, body mass index, presence of underlying diseases (such as diabetes, rheumatoid arthritis, and thyroid disease), follow-up length, and method of CTS assessment. The authors neither analyzed the data using an individual participant data meta-analysis (5) nor reported the prevalence and incidence of CTS according to important background characteristics, such as sex, age group, race/ethnicity, education, and occupation. In addition, the prevalence estimates for studies " $\mathrm{C}$ " and "E" were miscalculated.

Using a random-effects meta-analysis, the pooled prevalence of CTS is $7.09 \%$ (95\% CI 4.58-10.99\%) and the pooled incidence of CTS is $2.94 \%$ (95\% CI 1.68-5.14\%) (figure 1). The point estimates from the aggregated data meta-analyses do not show a major

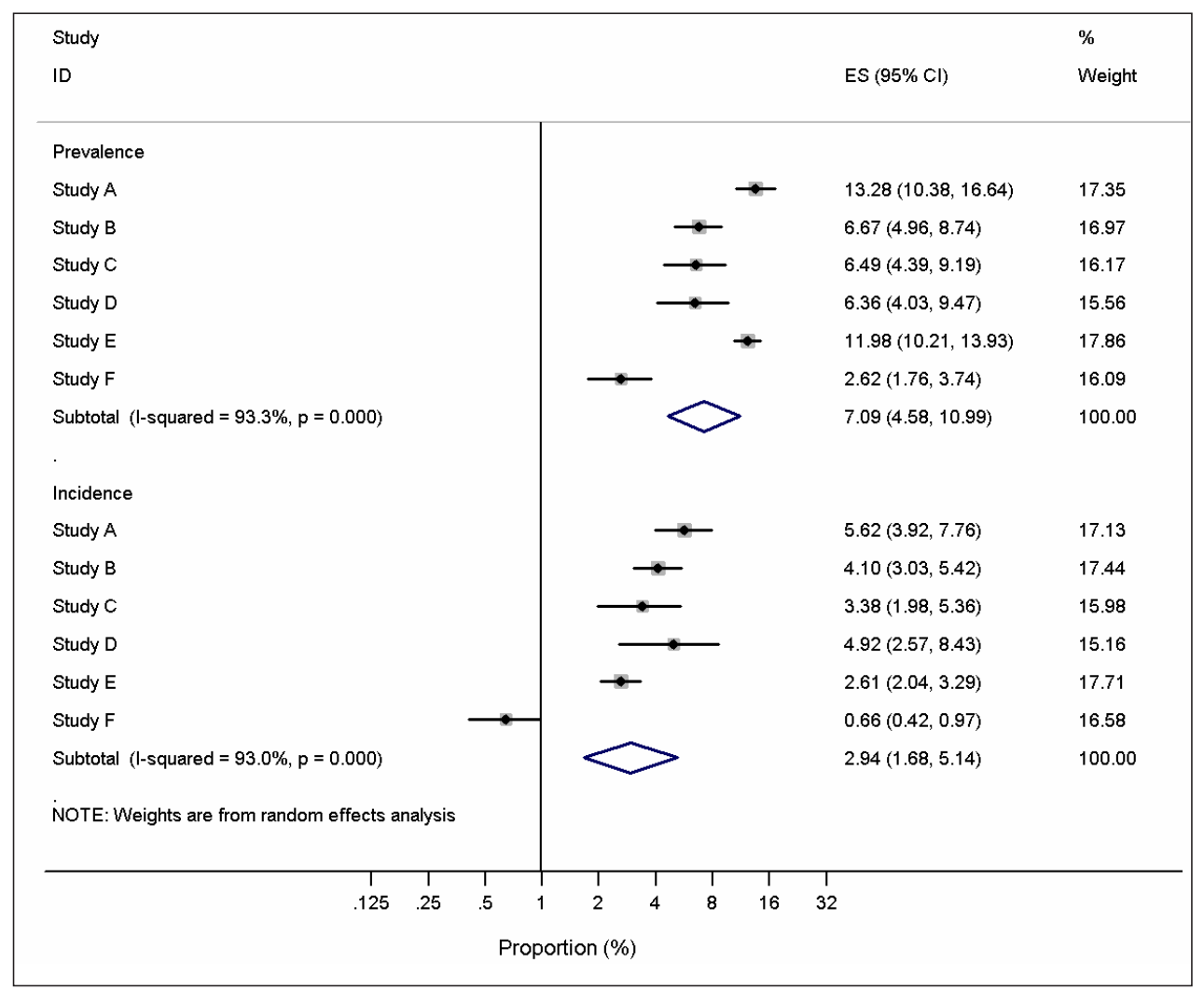

Figure 1. The pooled prevalence and incidence of carpal tunnel syndrome in six prospective studies in US working populations using a random-effects meta-analysis 
difference with those from simple pooling, but the confidence intervals are wide, indicating major uncertainty.

\section{References}

1. Dale AM, Harris-Adamson C, Rempel D, Gerr F, Hegmann K, Silverstein B, et al. Prevalence and incidence of carpal tunnel syndrome in US working populations: pooled analysis of six prospective studies. Scand J Work Environ Health. 2013;39(5):495-505. http://dx.doi.org/10.5271/sjweh.3351

2. Riley RD, Lambert PC, Abo-Zaid G. Meta-analysis of individual participant data: rationale, conduct, and reporting. BMJ. 2010;340:c221. http://dx.doi.org/10.1136/bmj.c221

3. Abo-Zaid G, Guo B, Deeks JJ, Debray TP, Steyerberg $\mathrm{EW}$, Moons $\mathrm{KG}$, et al. Individual participant data metaanalyses should not ignore clustering. J Clin Epidemiol. 2013;66(8):865-73 e4
4. Higgins JP, Thompson SG. Quantifying heterogeneity in a meta-analysis. Stat Med. 2002;21(11):1539-58. http://dx.doi.org/10.1002/sim.1186

5. Debray TP, Moons KG, Abo-Zaid GM, Koffijberg H, Riley RD. Individual participant data meta-analysis for a binary outcome: one-stage or two-stage? PLoS ONE. 2013;8(4):e60650. http:// dx.doi.org/10.1371/journal.pone.0060650

\section{Rahman Shiri, MD, PhD, MPH}

Centre of Expertise for Health and Work Ability, Finnish Institute of Occupational Health, Topeliuksenkatu 41 a $\mathrm{A}$

FIN-00250 Helsinki

[Email: rahman.shiri@ttl.fi] 